\section{Kidney \\ Blood Pressure Research}

Kidney Blood Press Res 2013;37:531-539

\title{
Effects of the Degree of Obesity on Achieving Target Blood Pressure and Metabolic Deterioration in Obese Individuals: A Population-Based Study
}

\author{
Serkan Ozturk ${ }^{a} \quad$ Davut Baltaci $^{\mathrm{b}} \quad$ Yasemin Turker $^{c} \quad$ Ali Kutlucan $^{\mathrm{d}} \quad$ Erhan Yengile $^{\mathrm{e}}$ \\ Mehmet Harun Deler ${ }^{b}$ Mucahit Gurd Handan Ankarali ${ }^{f}$
}

\begin{abstract}
${ }^{a}$ Abant Izzet Baysal University, School of Medicine, Department of Cardiology, Bolu; ' ${ }^{\circ}$ uzce University, School of Medicine, Department of Family Medicine, 'Family Health Office No: 3, dDuzce University, School of Medicine, Department of Internal Medicine, Duzce; eMustafa Kemal University, School of Medicine, Department of Family Medicine, Hatay; fDuzce University, School of Medicine, Department of Biostatistics, Duzce, Turkey
\end{abstract}

\section{Key Words}

Obesity $\bullet$ Target blood pressure $\bullet$ Body mass index $\bullet$ Metabolic disorders

\begin{abstract}
Background/Aims: This study aimed to evaluate the severity of obesity and its impact on achieving target blood pressure and metabolic derangement in obese individuals. Methods: This cross-sectional and population-based study was conducted between January and December 2012. A total of 1837 consecutive obese patients admitted to our outpatient clinic were enrolled. The anthropometric and blood pressure measurements, bioelectrical impedance fat analysis, blood sample analysis, impaired glucose status, metabolic syndrome, and insulin resistance of 1265 obese patients were compared between groups of patients separated by severity of obesity. Results: Only approximately one-third of patients with previous hypertension achieved normal blood pressure. In addition, the majority of patients without previous hypertension had higher blood pressure at the end of the study compared with baseline. The percent of patients with an impaired fasting blood glucose $\geq 100 \mathrm{mg} / \mathrm{dL}$ was $38.5 \%$. The frequency of impaired glucose tolerance was $39.1 \%$ in the patients who underwent OGTT. Body mass index (BMI) was associated with impaired blood glucose, hypertension, insulin resistance, and the development of metabolic syndrome. The incidences of metabolic syndrome, insulin resistance, impaired glucose tolerance, and uncontrolled blood pressure were significantly different between groups of differing obesity severity $(p<0.001, p<0.001$, $p=0.041$, and $p<0.001$, respectively). Conclusion: The severity of obesity was associated with the failure to achieve target blood pressure and metabolic syndrome. Based on our data, blood pressure and metabolic parameters in obese patients should be monitored frequently and treated with caution.
\end{abstract}

Copyright $(2013$ S. Karger AG, Basel 


\section{Kidney \\ Blood Pressure Research}

\section{Introduction}

Obesity is an epidemic and chronic disease worldwide. It is multi-factorial, and involves the integration of social, behavioral, cultural, physiological, metabolic, and genetic factors. It is defined as the excess accumulation of adipose tissue $[1,2]$, and significantly impacts the risk of mortality and morbidity. The prevalence of obesity has gradually increased over the last decade. Between 2003 and 2004, the prevalence of obesity was 31.1\% in males and $33.2 \%$ in females, which rose to $33.3 \%$ in males and $35.3 \%$ in females between 2005 and $2006[3,4]$. The obesity prevalence of some European countries was reported to be $5-23 \%$ in males and $7-36 \%$ in females [5-7]. In Turkey, the obesity prevalence is $12.9-25.7 \%$ in males, and $29.9-50.2 \%$ in females [8-10].

Obesity is associated with several health problems including abnormal blood pressure (BP), impaired glucose tolerance (IGT), vitamin deficiencies, and osteoarthritis $[11,12]$. In addition, BMI was strongly associated with systolic (SBP) and diastolic blood pressure (DBP) independent of age, alcohol intake, smoking habits, and sodium and potassium excretion. Approximately $30 \%$ of hypertensive patients were obese, and so hypertension (HT) is one of the most common obesity-related disorders $[13,14]$. Increased frequency of DM with increasing BMI has been reported in several populations. In addition, an increased frequency of IFG (impaired fasting glucose) and IGT, and the enhanced conversion of normal glucose tolerance to IGT and T2DM were significantly associated with increased BMI $[15,16]$. This study aimed to evaluate obesity staging and its effect on achieving target blood pressure and metabolic derangement in obese individuals admitted to primary care.

\section{Materials and Methods}

The cross-sectional and population-based study enrolled a total of 1837 adult patients who consecutively admitted to our outpatient clinic of family medicine for weight reduction, Duzce University, Department of Family Medicine within 1-year period (January 2012-December 2012). Out of 1837, 572 patients with previous or current diagnosis of T2DM and overweight, current anti-hyperlipidemia therapy, Hepatitis-B virus (HBV) (+), alcohol consumption and age under 18 years-old were excluded. Data of a total of 1265 patients was analyzed. Both anthropometric measurements and blood samples were routinely were obtained in the morning time, when the patients were overnight fasting. Anthropometric measurements such as weight, height, hip and waist circumferences were measured. BMI and Waist-Hip-Ratio (WHR) measures were calculated. Bioelectric impedance analysis (BIA) for total and visceral body fat was measured without shoes in light indoor clothes using a hand-to-foot single frequency biochemical impedance analyzer with $50 \mathrm{kHz}$ bioelectric impedance meter (Omron BF 510; Omron Corp. Kyoto, Japan) was used. Office-based BP values were recorded as mean of two measurements by 5 -minutes interval. Socio-demographic features such as gender and smoking status as current, former and non-smoker were noted. Additionally, previous medical history of the patients with respect to HT, T2DM, drug use, and etc were noted down.

Up to 10 milliliters of blood samples were drawn from the antecubital vein of each subject by applying minimal tourniquet pressure. Two $\mathrm{ml}$ of $10 \mathrm{ml}$-blood samples, which was used for the full blood count and glycosylated hemoglobin (HbA1c), was drawn into a vacutainer tube with ethylenediaminetetraacetic acid (EDTA). The remaining 6-8 milliliters were drawn into vacutainer tubes without anticoagulant for biochemical assay such as lipid profile, liver function tests, glucose, uric acid, high sensitive C-reactive protein (hs-CRP) and insulin. Status of insulin resistance (IR) was calculated (the original HOMA1-IR model) by homeostatic model assessment for insulin resistance (HOMA-IR), which was calculated with formula of [(fasting glucose $\mathrm{mg} / \mathrm{dL}$ ) $\times$ (fasting insulin $\mathrm{mIU} / \mathrm{mL}$ )/(405)] [17]. Oral tolerance was evaluated using 75 $\mathrm{g}$ oral glucose tolerance test (OGTT) was applied for the patients with FBG level $\geq 110 \mathrm{mg} / \mathrm{dL}$ according to American Diabetes Association (ADA) [18]. Also, spot urinary albumin-creatinine ratio (UACR) was obtained. In case of suspected any urinary infection or menstruation, spot urinary sampling was postponed and later assayed.

The patients were grouped into three groups according to BMI cut-off values. Group 1: $30 \leq \mathrm{BMI}<35$, group 2. $35 \leq \mathrm{BMI}<40$ and group 3 : $\mathrm{BMI} \geq 40[19]$. The patients were categorized into subgroups according 


\section{Kidney \\ Blood Pressure Research}

Kidney Blood Press Res 2013;37:531-539

DOI: 10.1159/000355733

Publisnea oninne: November 18, 2013

(C) 2013 S. Karger AG, Base

www.karger.com/kbr to BP, MetS, IR, and IGT status. The patients were classified into four subgroups as normal/optimal (SBP <120 and DBP $<80 \mathrm{~mm}-\mathrm{Hg}$ ), pre-HT stage (SBP: 120-139 and DBP: 80-89 $\mathrm{mm}-\mathrm{Hg}$ ), stage 1 (SBP: 140-159 and DBP: 90-99 mm-Hg), stage 2 (SBP: $\geq 160$ and DBP: $\geq 100 \mathrm{~mm}-\mathrm{Hg}$ ). Target BP value was accepted below $140 \mathrm{~mm}-\mathrm{Hg}$ for systolic and $90 \mathrm{~mm}-\mathrm{Hg}$ for diastolic BP value [20]. IR was set as positive if HOMAIR $\geq 2.5$, and negative if HOMA-IR $<2.5$ [21]. Criteria for Metabolic Syndrome (MetS) were evaluated according to National Cholesterol Education Program - Adult Treatment Panel (NCEP ATP III). MetS was accepted as the patients met three out of five criteria by both universal definitions. NCEP ATP III criteria were: waist circumference (WC) $>102$ $\mathrm{cm}$ (male) or $>88 \mathrm{~cm}$ (female); blood triglyceride (TG) level $\geq 150 \mathrm{mg} / \mathrm{dL}$, high density lipoprotein-cholesterol (HDLchol) $<40 \mathrm{mg} / \mathrm{dL}$ (male) or $<50 \mathrm{mg} / \mathrm{dL}$ (female), or under treatment of anti-lipid agents; blood pressure $\geq 130 / 85$ $\mathrm{mm}-\mathrm{Hg}$ or under treatment of anti-hypertensive agents; and FBG $\geq 110 \mathrm{mg} / \mathrm{dL}$ or presence of T2DM [22].

\section{Statistics}

SPSS version 15.0 was used for statistics. Both descriptive and analytic statistics were used. Descriptive statistics were stated as percentage, mean \pm SD (standard deviation) and number. Continues variables were stated as mean $\pm \mathrm{SD}$, whereas categorical variables as number and frequency. Chi-square/Fischer's test was used for comparisons between categorical variables. Normal distribution of continues variables were tested with Kolmogorov-Smirnov test. Comparisons of continues variables which were normally distributed between more than two groups were done by using One-way Analysis of Variance (ANOVA-Bonferroni test). Logistic transformation was applied for variables which were normally distributed. Values of LDL-chol, TG, insulin, HOMA-IR, UACR, uric acid and hs-CRP were not normally distributed and stated as adjusted and non-adjusted in tables. For statistical analysis, adjusted values of those variables were used. Comparisons between status of target blood pressure among patients with previously HT and each factors were including age (years), gender, status of metabolic syndrome, smoking, insulin resistance were performed with logistic regression analysis with adjustment for those confounding factors. Results are expressed as adjusted odd ratio (OR) with 95\% confidence interval (CI). Significance was accepted if $\mathrm{p}$ value was less than 0.05 .

\section{Ethics}

The data of the patients were obtained from medical records of hospital registry. Ethical approval was obtained from Ethic Committee of our institute and directory of our hospital. The procedures were in accordance with the ethical standards of the responsible committee on human experimentation (institutional or regional) and with the Helsinki Declaration of 1975, which was revised in 1983.

\section{Results}

Table 1 showed the socio-demographic and clinical features of the patients. The frequency of female and male was 79.9\% $(n=1012)$ and $20.1 \%(n=253)$, respectively. The ratio of current smokers was $14.5 \%(n=184)$. The average total body and visceral fat compositions on bioelectric impedance analysis were $43.7 \pm 8.4$ and $11.4 \pm 4.1 \%$. The frequency of the patients with previously diagnosed HT was $15.6 \%(n=196)$. Only about onethird of them $(n=68,34.7 \%)$ were at target ranges of BP. Majority of the hypertensive patients under hypertensive treatment $(n=128,65.3 \%)$ was not target BP values. About $37.0 \%$ of the
Table 1. Basic socio-demographic and medical features of the study population

\begin{tabular}{|c|c|}
\hline Variables $(n=1265)$ & $\mathrm{N},(\%)$ \\
\hline \multicolumn{2}{|l|}{ Gender } \\
\hline Female & $1012(80.0)$ \\
\hline Male & $253(20.0)$ \\
\hline \multicolumn{2}{|l|}{ Smoking Status } \\
\hline Non-smoker & $(70.4)$ \\
\hline The former & (15.1) \\
\hline The Current & (14.5) \\
\hline \multicolumn{2}{|l|}{ Previous HT (n=196, 15.6\%) } \\
\hline $\mathrm{BP}$ at target values & $68(34.7)$ \\
\hline BP not at target values & $128(65.3)$ \\
\hline \multicolumn{2}{|l|}{ HT stages among patients } \\
\hline without previous HT $(n=1069)$ & $404(37.8)$ \\
\hline Normal & $182(17.1)$ \\
\hline Pre-HT & $304(28.4)$ \\
\hline Stage 1 & $179(16.7)$ \\
\hline Stage 2 & \\
\hline $\operatorname{MetS}(+)$ & $689(54.5)$ \\
\hline $\operatorname{IR}(+)$ & 755 (59.7) \\
\hline \multicolumn{2}{|l|}{ Glycemic Status } \\
\hline Normoglycemia $(<100$ & $630(49.8)$ \\
\hline $\mathrm{mg} / \mathrm{dL})$ & $487(38.5)$ \\
\hline IFG $(\geq 100 \mathrm{mg} / \mathrm{dL})$ & $148(11.7)$ \\
\hline IFG $(\geq 110 \mathrm{mg} / \mathrm{dL})$ & \\
\hline \multicolumn{2}{|l|}{ OGTT results $(n=148)$} \\
\hline IFG & $79(53.4)$ \\
\hline IGT & $58(39.1)$ \\
\hline Newly diagnosed DM & $11(7.5)$ \\
\hline
\end{tabular}




\section{Kidney Blood Pressure Research}

Table 2. Basic biochemical parameters, anthropometric measurements and BIA fat composition analysis of the patients. SD: Standard deviation

\begin{tabular}{lclc}
\hline Variables & Mean \pm SD (Min-max) & Variables & Mean \pm SD (Min-max) \\
\hline LDL-chol (mg/dL) & $120.1 \pm 42.2(24.2-239.3)$ & Age (years) & $39.1 \pm 11.9(18-80)$ \\
Adjusted & $2.05 \pm 0.12$ & & \\
TG (mg/dL & $148.6 \pm 83.8(27-763)$ & SBP (mm-Hg) & $129.1 \pm 18.6(110-240)$ \\
Adjusted & $2.11 \pm 0.21$ & & $83.7 \pm 12.7(65-140)$ \\
HDL-chol (mg/dL) & $47.8 \pm 11.8(21-107.5)$ & DBP (mm-Hg) & $43.7 \pm 5.6(24.1-53.6)$ \\
FBG (mg/dL) & $97.5 \pm 9.8(67-125)$ & BIA-total fat (\%) & $11.43 \pm 4.1(5-29)$ \\
Insulin & $13.7 \pm 10.7(1.03-114)$ & BIA-visceral fat $(\%)$ & \\
Adjusted & $1.03 \pm 0.32$ & & $161.6 \pm 8.7(141.2-192.3)$ \\
HOMA-IR & $3.4 \pm 2.6(0.24-32.1)$ & Height (cm) & $96.5 \pm 16.1(71.4-164.3)$ \\
Adjusted & $0.41 \pm 0.33$ & & $104.9 \pm 10.6(85.7-151.8)$ \\
HbA1c (\%) & $5.5 \pm 0.4(3.6-6.4)$ & Weight $(\mathrm{kg})$ & $120.9 \pm 11.5(89.8-156.5)$ \\
ALT & $24.6 \pm 18.8(4.5-238)$ & WC $(\mathrm{cm})$ & $36.8 \pm 5.6(29.9-63.6)$ \\
AST & $23.2 \pm 13.9(2.3-201)$ & HC $(\mathrm{cm})$ & \\
UACR (mg/g) & $22.1 \pm 49.1(0.01-345)$ & BMI (kg/m²) & \\
Adjusted & $0.79 \pm 0.72$ & WHR & $0.85 \pm 0.07(0.78-1.01)$ \\
Uric acid (mg/dL) & $5.1 \pm 1.3(0.6-9.6)$ & Female & $0.93 \pm 0.06(0.88-1.25)$ \\
Adjusted & $0.68 \pm 0.12$ & Male & \\
hs-CRP (mg/dL) & $5.5 \pm 5.7(0.01-54.5)$ & & \\
Adjusted & $0.55 \pm 0.44$ & & \\
\hline SD: Standard deviation & & &
\end{tabular}

patients without previous HT $(n=404)$ were between normal ranges of blood pressure. More than half the patients had higher blood pressure values than normal. Accordingly, 17.1\% $(\mathrm{n}=182), 25.8 \%(\mathrm{n}=277), 15.1 \%(\mathrm{n}=161)$ of the patients were at level of pre-HT, stage 1 and stage 2, respectively. We detected isolated systolic HT in $4.2 \%$ of the patient without previous HT. The frequency of MetS was $54.5 \%(n=689)$ among study population. Majority of the patients $(n=755,59.7 \%)$ had insulin resistance. IFG ( $\geq 100 \mathrm{mg} / \mathrm{dL}$ ) was seen in $38.5 \%$ of the obese patients $(n=487)$. The ratio of the patients whose IFG was $\geq 110 \mathrm{mg} / \mathrm{dL}$ was $11.7 \%$ of $(\mathrm{n}=148)$. OGTT was applied those patients. Based on OGTT results, IFG, IGT and newly diagnosed T2DM were observed in $53.4 \%, 39.1 \%$, and $7.5 \%$ of those patients (Table 1). Basic biochemical parameters, anthropometric measurements and BIA fat composition analysis of the patients were given in Table 2. Mean age $39.5 \pm 11.9$ years-old (18-79). BMI was $35.5 \pm 8.4 \mathrm{~kg} / \mathrm{m}^{2}$. SBP and DBP were $129.4 \pm 18.6$ and $83.7 \pm 12.7 \mathrm{~mm}-\mathrm{Hg}$.

Out of 1265 patients, $45.9 \%(n=581), 30.2 \%(n=382)$ and $23.9 \%(n=302)$ were at group 1 , group 2 and group 3 of obesity level, when the patients were classified according to BMI. The ratio of the patients whose blood pressure was between normal ranges was significantly higher among the patients in group 1, compared to those in group 2 and $3(n=246,54.4 \%$ versus $n=116,39.3 \%$ and $n=53,24.2 \%$, respectively). On the other hand, the ratio of the patients with stage 2 HT was comparably higher in patients in group 3 versus group 1 and 2 $(\mathrm{n}=54,24.7 \%, \mathrm{n}=29,11.5 \%$ and $\mathrm{n}=29,6.4 \%$, respectively; $\mathrm{p}<0.001)$. The highest ratio of the patients previously treated with anti-hypertensive agents, who were out of target range of blood pressure was observed in group of 3 versus group 1 and 2 (15.8\% versus $51.7 \%$ and $36.5 \%$, respectively; $\mathrm{p}<0.001$ ) (Table 4). The frequencies of IR and MetS were significantly associated with obesity severity. $68.4 \%$ of the patients had IR in group 3, whereas $47.1 \%$ in group 1 had IR ( $\mathrm{p}<0.001)$. Furthermore, the frequency of patients with MetS in groups of obesity 1,2 and 3 was $42.6 \%, 61.4 \%$ and $68.4 \%(p<0.001)$. The ratio the patients who had IFG in groups 3 and 2 had more significantly higher than group 1 (48.1\% and $41.1 \%$ versus $30.8 \%$; $<0.001$ ). Moreover, the number of the patients with IGT in groups 3 and 2 was higher, compared to in group $1(35.7 \% ; 42.1 \%$ and $63.3 \%$; respectively; $\mathrm{p}=0.041$ ) (Table 3).

Table 4 indicated comparisons of biochemical and clinical features of the patients between groups of obesity severity. Mean age of the patients in group 1 was significantly different than in groups 2 and 3. It was observed that BMI was significantly different 


\section{Kidney Blood Pressure Research}

Table 3. Comparison of metabolic syndrome, insulin resistance, impaired glucose, blood pressure status of the patients between obesity stages. ${ }^{\alpha}$ Significance between groups was evaluated applying chi-square test. ${ }^{\beta}$ Values of variables was given mean \pm standard deviation (SD)

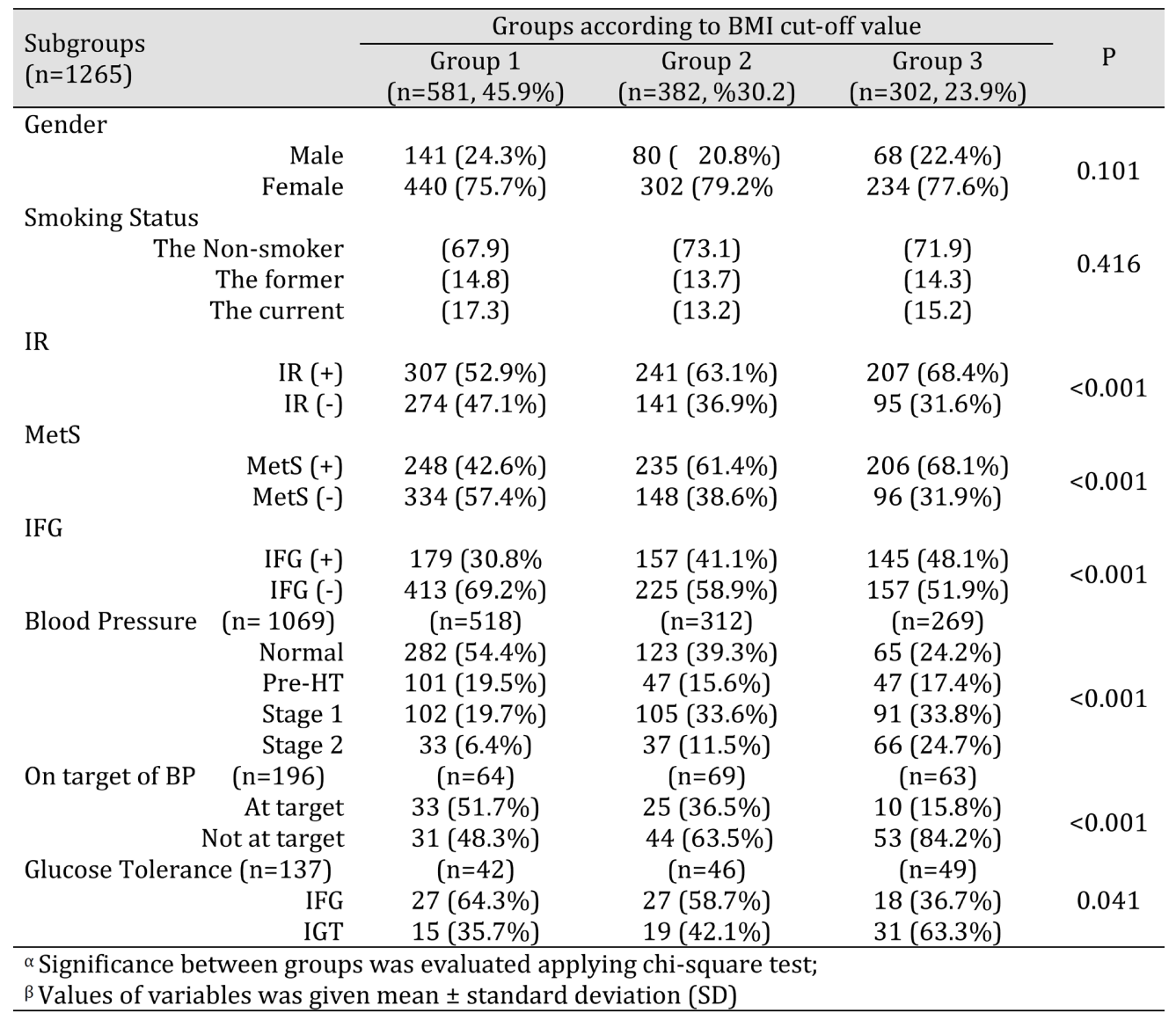

between groups of obesity severity, $(\mathrm{p}<0.001)$. Mean WHR measures among male and female patients between groups were not significantly different. On body fat composition analysis, both total and visceral body fat compositions were significantly different between groups. Compared to total fat composition, body visceral fat composition analysis between groups revealed clinically significant differences $(9.8 \pm 1.6 \%, 10.9 \pm 3.2 \%$, and $12.3 \pm 1.6$ $\%$; $\mathrm{p}$ 0.001). Comparisons of mean LDL-chol and HDL-chol between groups revealed no significant differences ( $\mathrm{p}=0.427, \mathrm{p}=0.151$ respectively). However, mean TG level in group 1 was significantly lower than in groups 2 and $3(p=0.006$ and $p=0.015$, respectively), but not significant between group 2 and 3 ( $p=0.510$ ). Mean FBG, insulin, HOMA-IR and HbA1c values in group 1 were significantly different than in group 2 and 3 , but not significant difference was observed between group 2 and 3. Spot UACR was significantly higher in groups 3 and 2, compared to group $1(24.8 \pm 52.5 \mathrm{mg} / \mathrm{g}, 26.2 \pm 51.3 \mathrm{mg} / \mathrm{g}$ and $16.4 \pm 43.6 \mathrm{mg} / \mathrm{g} ; \mathrm{p}=0.008$, $\mathrm{p}=0.001$ and $\mathrm{p}=0.445$, respectively). Mean serum uric acid and hs-CRP levels showed similar pattern. Uric acid and hs-CRP level in group 3 was comparably higher than in group 1 and 2 , but their values in group 2 were significantly lower than others $(p=0.028, p<0.001$ and $\mathrm{p}=0.007$ for uric acid; $\mathrm{p}=0.004, \mathrm{p}<0.001$ and $\mathrm{p}=0.020$ for hs-CRP).

In table 5, logistic regression analysis for age, obesity degree, status of smoking, gender, metabolic syndrome and insulin resistance at achieving target blood pressure among the obese patients with previously diagnosed HT was given. Accordingly, current smokers among the patients with previous HT were at great risk with two-fold for poor target blood pressure compared to non-smokers, but not significant (Odds ratio: 2.381; CI: 0.508-11.160), $\mathrm{p}=0.071$ ). Being male versus female, presence or absence of MetS and IR 


\section{Kidney \\ Blood Pressure Research}

Table 4. Comparison of anthropometric and blood pressure measurements, lipid profile, insulin resistance, body fat analysis, uric acid and hs-CRP between groups of obesity stages. ${ }^{\alpha}$ Statistically significance between groups was evaluated applying ANOVA. P1, P2 and P3 indicate significance between group 1 and 2; group 1 and 3; and group 2 and 3, respectively. ${ }^{\beta}$ Values of variables was given mean \pm standard deviation (SD)

\begin{tabular}{|c|c|c|c|c|}
\hline \multirow[b]{2}{*}{ Variables } & \multicolumn{3}{|c|}{ Groups according to BMI cut-off value } & \multirow{2}{*}{$\begin{array}{c}\mathrm{P}^{\alpha} \\
(\mathrm{P} 1, \mathrm{P} 2 \text { and } \mathrm{P} 3)\end{array}$} \\
\hline & $\begin{array}{c}\text { Group 1 } \\
\text { Mean } \pm \text { SD }\end{array}$ & $\begin{array}{c}\text { Group } 2 \\
\text { Mean } \pm \text { SD }\end{array}$ & $\begin{array}{c}\text { Group } 3 \\
\text { Mean } \pm \text { SD }\end{array}$ & \\
\hline Age (years-old) & $45.1 \pm 8.9$ & $37.8 \pm 8.4$ & $41.2 \pm 9.1$ & $\begin{aligned} & 0.001 \\
0.009, & <0.001,0.185 \\
& <0.001\end{aligned}$ \\
\hline $\begin{array}{l}\text { BMI }\left(\mathrm{kg} / \mathrm{m}^{2}\right) \\
\text { WHR }\end{array}$ & $32.9 \pm 1.8$ & $37.6 \pm 1.7$ & $47.8 \pm 5.4$ & $\begin{aligned}<0.001, & <0.001,<0.001 \\
& <0.001\end{aligned}$ \\
\hline $\begin{array}{r}\text { Male } \\
\text { Female }\end{array}$ & $\begin{array}{l}0.94 \pm 0.05 \\
0.87 \pm 0.02\end{array}$ & $\begin{array}{l}0.95 \pm 0.07 \\
0.86 \pm 0.07\end{array}$ & $\begin{array}{l}0.97 \pm 0.07 \\
0.84 \pm 0.01\end{array}$ & $\begin{array}{c}0.164,0.114,0.848 \\
0.280,0.102,0.192 \\
<0.001\end{array}$ \\
\hline $\mathrm{SBP}(\mathrm{mm}-\mathrm{Hg})$ & $129.8 \pm 26.5$ & $129.7 \pm 13.3$ & $140.6 \pm 18.2$ & $\begin{aligned}<0.001, & <0.001,<0.001 \\
& <0.001\end{aligned}$ \\
\hline $\mathrm{DBP}(\mathrm{mm}-\mathrm{Hg})$ & $86.6 \pm 13.5$ & $85.4 \pm 10.1$ & $90.6 \pm 10.2$ & $\begin{aligned}<0.001, & <0.001,<0.001 \\
& <0.001\end{aligned}$ \\
\hline BIA total $(\%)$ & $46.4 \pm 2.6$ & $45.3 \pm 4.8$ & $47.6 \pm 7.3$ & $\begin{aligned}<0.001, & <0.001,<0.001 \\
& <0.001\end{aligned}$ \\
\hline BIA visceral (\%) & $9.8 \pm 1.6$ & $10.9 \pm 3.2$ & $12.3 \pm 1.6$ & $<0.001,<0.001,<0.001$ \\
\hline LDL-chol (mg/dL) & $124.8 \pm 35.8$ & $112.4 \pm 35.9$ & $106.6 \pm 22.6$ & 0.379 \\
\hline Adjusted & $2.05 \pm 0.12$ & $2.05 \pm 0.11$ & $2.05 \pm 0.13$ & $0.889,0.646,0.510$ \\
\hline $\mathrm{TG}(\mathrm{mg} / \mathrm{dL})$ & $138.2 \pm 62.9$ & $204.7 \pm 124.2$ & $147.5 \pm 81.2$ & 0.002 \\
\hline Adjusted & $2.13 \pm 0.21$ & $2.16 \pm 0.20$ & $2.16 \pm 0.189$ & $\begin{array}{c}0.006,0.015,0.720 \\
0.028\end{array}$ \\
\hline HDL-chol (mg/dL) & $55.2 \pm 7.1$ & $45.2 \pm 7.2$ & $47.6 \pm 7.2$ & $\begin{array}{c}0.334,0.052,0.367 \\
<0.001\end{array}$ \\
\hline $\mathrm{FBG}(\mathrm{mg} / \mathrm{dL})$ & $101.2 \pm 11.6$ & $98.4 \pm 11.8$ & $100.2 \pm 8.3$ & $0.002,<0.001,0.105$ \\
\hline Insulin $(\mathrm{IU} / \mathrm{mL})$ & $5.6 \pm 4.3$ & $9.8 \pm 8.4$ & $17.1 \pm 9.0$ & $<0.001$ \\
\hline Adjusted & $0.91 \pm 0.35$ & $1.01 \pm 0.36$ & $1.06 \pm 0.35$ & $0.017,<0.001,0.198$ \\
\hline HOMA-IR & $1.4 \pm 1.1$ & $2.5 \pm 2.2$ & $4.3 \pm 2.3$ & $<0.001$ \\
\hline Adjusted & $0.30 \pm 0.35$ & $0.38 \pm 0.38$ & $0.45 \pm 0.35$ & $\begin{array}{c}0.009,<0.001,0.143 \\
0.002\end{array}$ \\
\hline HbA1c (\%) & $5.3 \pm 0.4$ & $5.5 \pm 0.5$ & $5.5 \pm 0.4$ & $0.005,0.005,0.906$ \\
\hline UACR (mg/g) & $16.4 \pm 43.6$ & $26.2 \pm 51.3$ & $24.8 \pm 52.5$ & 0.011 \\
\hline Adjusted & $0.67 \pm 0.59$ & $0.91 \pm 0.68$ & $0.73 \pm 0.76$ & $0.008,0.001,0.445$ \\
\hline Uric acid (mg/dL) & $5.5 \pm 1.4$ & $4.8 \pm 0.8$ & $5.8 \pm 1.2$ & $<0.001$ \\
\hline Adjusted & $0.67 \pm 0.12$ & $0.69 \pm 0.13$ & $0.72 \pm 0.10$ & $0.028,<0.001,0.007$ \\
\hline hs-CRP (mg/dL) & $5.8 \pm 4.4$ & $5.5 \pm 3.6$ & $7.5 \pm 4.3$ & $<0.001$ \\
\hline Adjusted & $0.46 \pm 0.46$ & $0.54 \pm 0.38$ & $0.71 \pm 0.43$ & $0.004,<0.001,0.020$ \\
\hline
\end{tabular}

was not significantly associated with risk for poor target blood pressure (Odds ratio: 0.484; CI: 0.144-0-1.624, $\mathrm{p}=0.240$; Odds: 1.712 , CI: 0.707-4.203, $\mathrm{p}=0.231$; and Odds: 1.412 , CI: $0.647-3.129, \mathrm{p}=0.381$ ). However, the patients with $\mathrm{BMI} \geq 40 \mathrm{~kg} / \mathrm{m}^{2}$ had great increased risk about 7 times above desired target blood pressure, compared to those with BMI $\geq 30 \mathrm{~kg} / \mathrm{m}^{2}$ (Odds: 6.998; CI: 2.608-18.782).

\section{Discussion}

The indications of this study in obese patients were that metabolic deterioration was significant, and achieving target blood pressure was challenging. In addition, many obese patients were not being treated for hypertension. The present study demonstrated that increased BMI was associated with impaired blood glucose tolerance, hypertension, 


\section{Kidney Blood Pressure Research}

Kidney Blood Press Res 2013;37:531-539

DOI: 10.1159/000355733

C 2013 S. Karger AG, Basel

www.karger.com/kbr insulin resistance, and the development of metabolic syndrome. It also revealed that achieving target blood pressure control was impaired at increased BMIs.

Our observations on the frequency of the BP range were consistent with previous studies. Oduwole et al. reported that hypertensive BPs among obese Nigerian adolescents were prevalent [23]. In addition, Benmohammed et al. reported that hypertension and arterial stiffness were associated with abdominal adiposity [24]. A recent study indicated that smoking and high BMI are strong and independent risk factors associated with higher BP levels in patients with uncontrolled arterial hypertension [25]. Consistent with this, we found that a failure to achieve target BP in obese hypertensive patients was correlated with obesity staging. We also detected an increase in HT frequency at higher BMIs. The failure to achieve target BPs and the increased prevalence of HT could be due to increased visceral adiposity and arterial stiffness.

The poorest BP control was observed in severely obese patients. Using logistic regression analysis, we determined that achieving target blood pressure was negatively associated with the degree of obesity.

It is well known that pre-diabetes and DM are significantly correlated with obesity, and that the conversion from normoglycemia to impaired glucose tolerance and DM is accelerated with increasing BMI $[26,27]$. In this study, we also found that the frequency of patients with IFG (38.5\%) and IGT (38.1\% of those who underwent OGTT) were consistent with previous reports. In addition, we observed that the proportion of IGT increased with the severity of obesity. We suggest, therefore, that impaired glucose is not only correlated with obesity but also with the degree of obesity. Insulin resistance (IR) and metabolic syndrome (MetS) were also positively correlated with the severity of obesity.

Studies on uric acid levels in obesity suggested that elevated serum uric acid levels were positively correlated with obesity, MetS, and atherosclerosis, and may have potential as an obesity-related indicator [28-30]. In this study, the severity of obesity also negatively impacted metabolic indices. Uric acid and high-sensitivity CRP (hs-CRP) values were also significantly higher. Insulin and fasting blood glucose levels, thus HOMA-IR, were significantly increased in patients with a BMI $\geq 40 \mathrm{~kg} / \mathrm{m}^{2}$, compared with those with a BMI $<40 \mathrm{~kg} /{ }^{2}$. We also observed a positive correlation between the frequency of MetS and degree of obesity. In addition, we studied serum hs-CRP levels and its relationship with the degree of obesity. Our data were consistent with previous observations [31-34], where the extent of low-level inflammation was correlated with the degree of obesity. Based on the increase in serum levels of uric acid and hs-CRP in obesity, and their correlation with the degree of the obesity, we propose that uric acid levels may be a good marker for the inflammatory state in obesity.

Our study has some limitations. First, it was a cross-sectional. Secondly, blood pressure measurements were office-based, even though the mean of two blood pressure measurements was recorded. Thirdly, analysis was carried out without separating male and female subgroups due to a similar gender distribution between the groups of obesity severity. Finally, we also did not include analysis of the physical activity of the patients in the study.
Table 5. Logistic regression analysis for among the gression analysis for age, obesity degree, status of resistance at achieving target blood pressure among Confidence interval

\begin{tabular}{lcc}
\hline & Odds ratio (95\% CI) & $\mathrm{p}$ \\
\hline Age & $1.031(0.995-1.068)$ & 0.089 \\
$\begin{array}{c}\text { Smoking status } \\
\text { The Former }\end{array}$ & $0.906(0.330-2.488)$ & 0.848 \\
The Current & $2.381(0.508-11.160)$ & 0.271 \\
$\begin{array}{c}\text { Gender status } \\
\text { Male }\end{array}$ & $0.484(0.144-0-1.624)$ & 0.240 \\
$\begin{array}{c}\text { MetS Status } \\
\text { MetS (+) }\end{array}$ & $1.712(0.707-4.203)$ & 0.231 \\
$\begin{array}{c}\text { IR Status } \\
\text { IR (+) }\end{array}$ & $1.412(0.647-3.129)$ & 0.381 \\
$\begin{array}{c}\text { Obesity degree } \\
\text { Group 2 } \\
\text { Group 3 }\end{array}$ & $1.878(0.806-4.374)$ & 0.044 \\
\end{tabular}

Logistic regression analysis for age, obesity degree,
status of smoking, gender, metabolic syndrome and insulin resistance at achieving target blood pressure
among the obese patients with previously diagnosed HT, CI: Confidence interval 


\section{Kidney \\ Blood Pressure Research}

Ozturk et al.: Obesity, Target Blood Pressure and Metabolic Disorders

\section{Conclusion}

Obesity is a significant obstacle for achieving target blood pressures in hypertensive patients, and this effect is magnified with increasing levels of obesity. Higher degrees of obesity carry an increased risk of impaired glucose tolerance, insulin resistance, and the development of MetS. Obese patients should, therefore, be monitored frequently to achieve target blood pressures and control metabolic parameters.

\section{Conflict of Interest}

There is no conflict of interest between authors.

\section{Acknowledgements}

We thank health professionals for their help in the study. The study was not financially supported by any company.

\section{References}

1 Keller KB, Lemberg L: Obesity and the metabolic syndrome. Am J Crit Care 2003;12:167-170.

2 Nyholm M, Gullberg B, Råstam L, Lindblad U: What is the accurate prevalence of obesity in Sweden in the 21st century? Methodological experiences from the skaraborg project. Obesity (Silver Spring) 2008;16:896898.

3 Flegal KM, Carroll MD, Ogden CL, Johnson CL: Prevalence and trends in obesity among U.S. adults, 19992000. JAMA 2002;288:1723-1727.

-4 Ogden CL, Carroll MD, Curtin LR, McDowell MA, Tabak CJ, Flegal KM: Prevalence of overweight and obesity in the United States, 1999-2004. JAMA 2006;295:1549-1555.

5 International comparisons of obesity prevalence. National Obesity Observatory. 2009. Available from: http:// www.noo.org.uk/uploads/doc799_2_International_Comparisons_Obesity_Prevalence2.pdf (Accessed in May 2013).

-6 Zatońska K, Janik-Koncewicz K, Regulska-Ilow B, Ilow R, Różańska D, Szuba A, Einhorn J, Vatten L, Xiao-Mei M, Janszky I, Paprzycki P, Sulkowska U, Gozdziewska M, Manczuk M, Zatonski WA: Prevalence of obesity baseline assessment in the prospective cohort 'PONS' study. Ann Agric Environ Med 2011;18:246-250.

7 Schönbeck Y, Talma H, van Dommelen P, Bakker B, Buitendijk SE, Hirasing RA, van Buuren S: Increase in prevalence of overweight in Dutch children and adolescents: a comparison of nationwide growth studies in 1980, 1997 and 2009. PLoS One 2011;6:e27608.

8 Bagriacik N, Onat H, Ilhan B, Tarakci T, Ozsar Z, Ozyazar M, Hatemi HH, Yildiz G: Obesity profile in Turkey. Int J Diabetes Metab 2009;17:5-8.

- Iseri A, Arslan N: Obesity in adults in Turkey: age and regional effects. Eur J Public Health 2009;19:91-94.

10 Sanisoglu SY, Oktenli C, Hasimi A, Yokusoglu M, Ugurlu M: Prevalence of metabolic syndrome-related disorders in a large adult population in Turkey. BMC Public Health 2006;6:92.

11 Soysal A, Demiral Y, Soysal D, Ucku R, Koseoglu M, Aksakoglu G: The prevalence of metabolic syndrome among young adults in Izmir, Turkey. Anadolu Kardiyol Derg 2005;5:196-201.

12 Baltaci D, Kutlucan A, Ozturk S, Karabulur I, Yildirim HA, Celer A, Celbek G, Kara IH: Evaluation of vitamin B12 level in middle-aged obese womenwith metabolic and nonmetabolic syndrome: case-control study. Turk J Med Sci 2012;42:802-809.

13 Baltaci D, Erbilen E, Turker Y, Alemdar R, Aydin Y, Kaya A, Celer A, Cil H, Aslantas Y, Ozhan H: Predictors of hypertension control in Turkey: the MELEN study. Eur Rev Med Pharmacol Sci 2013;17:1884-1888. 


\section{Kidney \\ Blood Pressure Research}

14 Finucane MM, Stevens GA, Cowan MJ, Danaei G, Lin JK, Paciorek CJ, Singh GM, Gutierrez HR, Lu Y, Bahalim AN, Farzadfar F, Riley LM, Ezzati M, Global Burden of Metabolic Risk Factors of Chronic Diseases Collaborating Group (Body Mass Index): National, regional, and global trends in body-mass index since 1980: systematic analysis of health examination surveys and epidemiological studies with 960 country-years and $9 \bullet 1$ million participants. Lancet 2011;377:557-567.

15 Chihaoui M, Kanoun F, Ben Rehaiem B, Ben Brahim S, Ftouhi B, Mekaouar A, Fekih M, Mbazad A, Zouari B, Ben Khalifa F: Predictive risk factors for deterioration from normoglycemic state to type 2 diabetes mellitus or impaired glucose tolerance in a Tunisian urban population. Diabetes Metab 2001;27:487-495.

16 Lewis GF, Carpentier A, Adeli K, Giacca A: Disordered fat storage and mobilization in the pathogenesis of insulin resistance and type 2 diabetes. Endocr Rev 2002;23:201-229.

17 Matthews DR, Hosker JP, Rudenski AS, Naylor BA, Treacher DF, Turner RC: Homeostasis model assessment: insulin resistance and beta-cell function from fasting plasma glucose and insulin concentrations in man. Diabetologia 1985;28:412-419.

18 American Diabetes Association: Standards of medical care in diabetes-2007. Diabetes Care 2007;30:S4-S41.

19 Sturm R: Increases in morbid obesity in the USA: 2000-2005. Public Health 2007;121:492-496.

20 The Seventh Report of the Joint National Committee on Prevention, Detection, Evaluation, and Treatment of High Blood Pressure. NIH Publication No. 04-5230. August 2004. http://www.nhlbi.nih.gov/guidelines/ hypertension/jnc7full.pdf (Accessed in January 2011).

21 International Diabetes Federation. The IDF consensus worldwide definition of metabolic syndrome (article online). 2006 [http//www.idf.org.webdata/docs/IDF_Meta_def_final.pdf], Accessed May 1, 2012.

$\checkmark 22$ Executive summary of the Third Report on the National Cholesterol Education Program (NCEP) Expert Panel of Detection, Evaluation and Treatment of High Blood Cholesterol in Adults (Adult Treatment Panel III). JAMA 2001;265:2486-2487.

-23 Oduwole AA, Ladapo TA, Fajolu IB, Ekure EN, Adeniyi OF: Obesity and elevated blood pressure among adolescents in Lagos, Nigeria: a cross-sectional study. BMC Public Health 2012;12:616.

24 Benmohammed K, Nguyen MT, Khensal S, Valensi P, Lezzar A: Arterial hypertension in overweight and obese Algerian adolescents: role of abdominal adiposity. Diabetes Metab 2011;37:291-297.

-25 Chmiel C, Wang M, Senn 0, Del Prete V, Zoller M, Rosemann T, Steurer-Stey C: Uncontrolled arterial hypertension in primary care - patient characteristics and associated factors. Swiss Med Wkly 2012; 142:w13693.

26 Ko GT, Chan JC, Chow CC, Yeung VT, Chan WB, So WY, Cockram CS: Effects of obesity on the conversion from normal glucose tolerance to diabetes in Hong Kong Chinese. Obes Res 2004;12:889-895.

-27 Liu Y, Tong G, Tong W, Lu L, Quin X: Can body mass index, waist circumference, waist-hip ratio and waistheight ratio predict the presence of multiple metabolic risk factors in Chinese subjects? BMC Public Health 2011;11:35

28 Lee JM, Kim HC, Cho HM, Oh SM, Choi DP, Suh I: Association between serum uric acid level and metabolic syndrome. J Prev Med Public Health 2012;45:181-187.

29 Pacifico L, Cantisani V, Anania C, Bonaiuto E, Martino F, Pascone R, Chiesa C: Serum uric acid and its association with metabolic syndrome and carotid atherosclerosis in obese children. Eur J Endocrinol 2009;160:45-52.

-30 Oyama C, Takahashi T, Oyamada M, Oyamada T, Ohno T, Miyashita M, Saito S, Komatsu K, Takashina K, Takada G: Serum uric acid as an obesity-related indicator in early adolescence. Tohoku J Exp Med 2006;209:257262.

-31 Soriano-Guillén L, Hernández-García B, Pita J, Domínguez-Garrido N, Del Río-Camacho G, Rovira A: Highsensitivity C-reactive protein is a good marker of cardiovascular risk in obese children and adolescents. Eur J Endocrinol 2008;159:1-4.

-32 Huffman FG, Whisner S, Zarini GG, Nath S: Waist circumference and BMI in relation to serum high sensitivity C-reactive protein (hs-CRP) in Cuban Americans with and without type 2 diabetes. Int J Environ Res Public Health 2010;7:842-852.

33 Lee K, Song YM, Sung J: Which obesity indicators are better predictors of metabolic risk? Healthy twin study. Obesity (Silver Spring) 2008;16:834-480.

-34 Kabakci G, Aydin M, Demir I, Kirma C, Ozerkan F: Global cardiometabolic risk profile in patients with hypertension: results from the Turkish arm of the pan-European GOOD survey. Turk Kardiyol Dern Ars 2010;38:313-320. 